\title{
Use of STATCOM in wind farms with fixed-speed generators for grid code compliance
}

\author{
Dionisio Ramirez, Sergio Martinez, Francisco Blazquez, Carmelo Carrero
}

\begin{abstract}
A B S T R A C T
The increasing penetration of wind energy into power systems has pushed grid operators to set new requirements for this kind of generating plants in order to keep acceptable and reliable operation of the system. In addition to the low voltage ride through capability, wind farms are required to participate in voltage support, stability enhancement and power quality improvement. This paper presents a solution for wind farms with fixed-speed generators based on the use of STATCOM with braking resistor and additional series impedances, with an adequate control strategy. The focus is put on guaranteeing the grid code compliance when the wind farm faces an extensive series of grid disturbances.
\end{abstract}

\section{Introduction}

The increasing penetration of wind energy into power systems has pushed grid operators to set new requirements for this kind of generating plants in order to keep acceptable and reliable operation of the system $[1-5]$. One of the most relevant grid code requirements is the Low Voltage Ride Through (LVRT) capability of wind generators. In case of a voltage sag in the connection point of the farm, typically due to a short-circuit in some point of the network, the generators must remain connected instead of tripping. The grid codes define the characteristics of the voltage sag to be withstood, in terms of duration, depth, and time profile.

To achieve the optimum efficiency in the conversion from the kinetic energy of wind to the mechanical energy in the turbine shaft, modern wind generators are able to vary their speed, by means of power electronic converters. With an adequate control scheme, these converters can be used to provide LVRT capability to the generators, what has been the subject of important technological developments in the past years, e.g. [6]. However, modern variable speed generators are not the only ones installed in wind farms. There are an important amount of fixed speed wind generators still in use that have to be upgraded to the new grid code requirements. So, different solutions have been proposed [7-9].

Once the technological milestone of LVRT capability of wind farms has been surpassed, the current step in grid integration of renewable energy is its participation in other ancillary services, as voltage support [10], stability enhancement [10,11], and power quality improvement [12-14]. Recent grid codes of power systems with high wind generation penetration already include requirements in these related issues. As an example, Fig. 1 shows the admissible operating point (shaded area) of a wind farm during a grid fault and the subsequent recovery period, as a function of the voltage at the connection point, in the case of the Spanish grid code [4]. Similar requirements are set by other codes.

As an alternative to series compensation [6,8], the STATCOM $[7,12,14]$, is a common solution for the LVRT problem in wind farms with fixed speed generators and, in addition, it can be used for complying with new grid codes. The work described in this paper is a test-based comprehensive investigation on the behavior of such STATCOM when the wind farm faces a voltage sag in the grid it is connected to. It is shown that different types of sags impose different demands to the STATCOM that the control system has to robustly deal with (LVRT capability), while complying with other code requirements for grid integration. This paper proposes hardware solutions that complement the STATCOM for all the possible situations. The work includes the development of an adequate control scheme, the description of the necessary equipment, its implementation in a test bench with a scaled wind generator, and extensive testing of the whole system in an electrical network with a voltage sag generator.

The paper deepens in the work presented in [7], in which threephase faults are studied from the point of view of transient stability, by dealing with the problem of single-phase and phase-to-phase sags. In addition, it takes into account the special restrictions imposed by new grid codes on the reactive power regulation of wind farms during voltage sags (see Fig. 1), while addressing other 


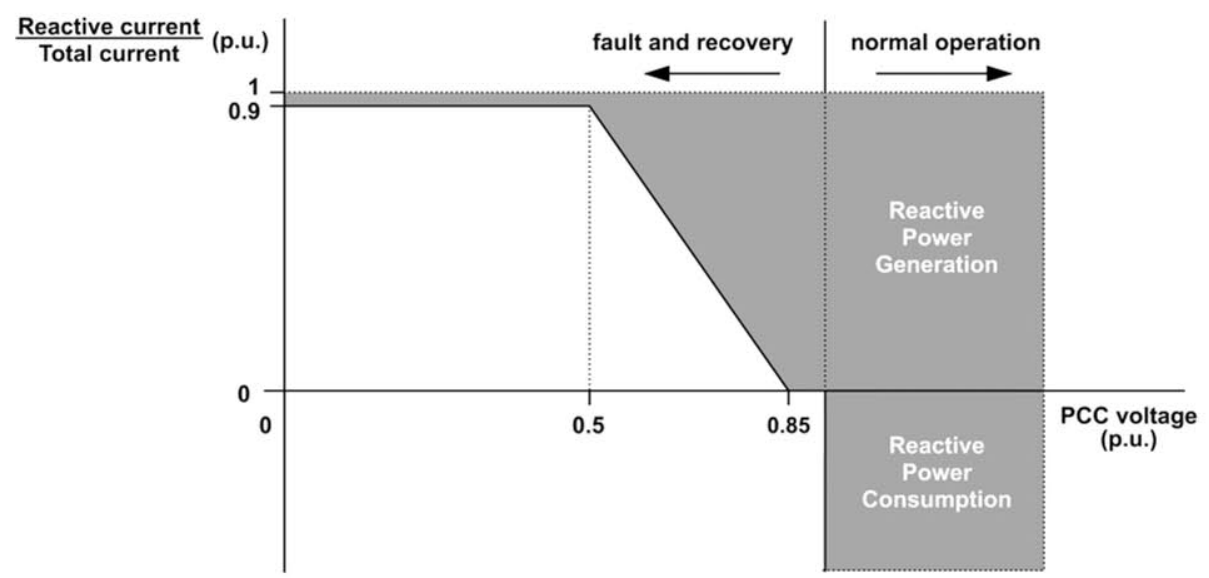

Fig. 1. Spanish grid code [4]. Admissible operating point during the fault period and the voltage recovery period, as a function of the voltage at the connection point.

related problems like the undervoltage disconnection of generators, and the differences associated with nearby or distant faults.

Thus, the main contribution of the paper can be resumed as the use and control of STATCOM for facing voltage sags taking into account: the practical issues in actual wind farms with fixed speed generators, the active-reactive power management during voltage disturbances for complying with new grid codes, and the integral interaction with the generators and with the grid. Particularly: it addresses the peculiarities of distant and near faults; it studies every possible fault type, balanced and unbalanced; and it explores and takes into account the coordination with the undervoltage protection of generators.

Section 2 of the paper introduces the different types of voltage dips to be withstood by the wind farm. Section 3 describes the control system implementing the LVRT and code compliance capabilities. Section 4 describes the system developed to test the STATCOM behavior, compiles the experimental results and presents the analysis for every possible grid fault, balanced and unbalanced, distant or near the wind farm.

\section{Voltage sags due to grid faults}

Voltage sags are a relatively common disturbance in power systems [15]. The connection of a large load at a given point of an electrical network causes a temporary voltage depression that is propagated to the nearby buses. These are balanced voltage sags, characterized by a slight depth, and, normally, they are not a great problem for wind generators.

Faults in the grid are the other cause of voltage sags. A shortcircuit can be balanced (three-phase) or unbalanced (phase to phase or single-phase), with a wide range of depths. This variety of situations is the real challenge the wind farms have to face, particularly, those equipped with fixed speed generators, their additional STATCOM, and the control system, that constitute the object of the work described in this paper.

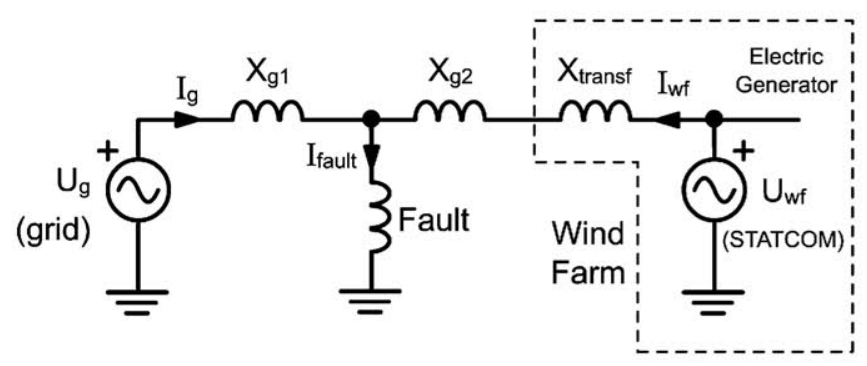

Fig. 2. Distant grid fault.
In addition to the abovementioned types of short circuits, the work presented in this paper studies the effect of the depth of the voltage sag. Or, in other words, the distance from the bus of the grid where the wind farm is connected to the point of the network where the fault has taken place.

\subsection{Distant faults}

Apart from those due to the connection of large loads, the slightest voltage sags at the terminals of a wind farm are due to faults in points of the network far from the point of connection of the plant, or with large fault impedance.

Fig. 2 shows the simplified single-phase equivalent circuit for a distant three-phase short-circuit (letter symbol $u$ stands for voltage, $i$ for current, and descriptions of all the subscripts used in the paper can be found in Table 1). Since the figure is only intended to illustrate the general behavior of the main elements involved, these are represented in a very simplified form. All the impedances are shown with their inductive part. The grid is represented by its Thevenin equivalent circuit as seen from the point of fault, split in two parts: the contribution of the wind farm (right side of the point of fault, including the line reactance $X_{g 2}$ ), and that of the rest of the power system (left side of the fault, $U_{g}$ and $X_{g_{1}}$ ). The plant limits are displayed with dotted line, and the only plant elements represented are the transformer (by means of the short-circuit reactance, $X_{\text {transf }}$ ) and the STATCOM (as a voltage source, $U_{w f}$ ).

During the voltage sag, in this case, the STATCOM injects reactive power so that the voltage rises in the wind farm, what allows the wind generators to remain connected (LVRT capability). In addition, the injection of reactive power contributes to the voltage support of the outer power system, complying with code requirements (e.g., entering in the shaded area of Fig. 1).

\subsection{Nearby faults}

The deepest voltage sags a wind farm (or any other element of a power system) has to face are those due to faults, with small fault

\begin{tabular}{ll}
$\begin{array}{l}\text { Table } \mathbf{1} \\
\text { Subscripts. }\end{array}$ \\
\hline$\alpha-\beta$ & Static reference frame \\
$\mathrm{d}-\mathrm{q}$ & Rotating reference frame \\
$\mathrm{g}$ & Grid \\
$\mathrm{n}$ & Negative sequence \\
$\mathrm{p}$ & Positive sequence \\
$\mathrm{wf}$ & Wind farm \\
\hline
\end{tabular}




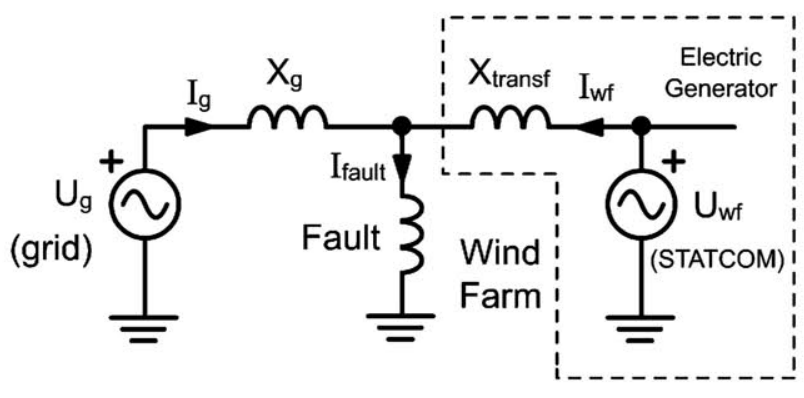

Fig. 3. Nearby grid fault.

impedance, in points of the network close to the point of connection of the farm. The limit situation would be a zero-impedance fault in the point of coupling.

Fig. 3 shows the simplified single-phase equivalent circuit for a three-phase short-circuit at the grid side terminals of the transformer of the wind plant. Compared with Fig. 2, $\mathrm{X}_{\mathrm{g} 2}$ is zero, $X_{\mathrm{g} 1}$ becomes $X_{g}$, and the series impedance between the STATCOM and the point of fault is very small (the short-circuit impedance of the transformer, $X_{\text {transf }}$ ).

In this case, it is very difficult to restore the voltage in the wind farm, because it requires a high current level from the STATCOM. If the fault impedance is very small, the required current can be higher than the maximum and it turns impossible to maintain the voltage.

This is not very important from the point of view of the power system and, in fact, grid codes do not require the voltage restoration. However, from the point of view of LVRT capability of the farm, if the voltage in the generators is very low, there is risk of generator tripping. To restore the voltage level in the farm during voltage sags due to nearby faults, one possible solution is the series connection of inductors or resistors [16], as shown in Fig. 4 ( $\left.X_{\text {additional }}\right)$. They remain short-circuited in normal operation, and the switches open in case of voltage sag. Thus, the series impedance between the plant and the fault is artificially augmented and the STATCOM is able to restore the voltage to acceptable levels and to avoid the generators tripping.

\section{Control system}

Grid codes do not impose the restoration of the grid voltage within specific limits during the voltage dip. However, they set requirements on the reactive power generation to contribute to the voltage recovery of the power system. To be more precise, for example, according to [4], the current supplied to the grid by the wind farm has to comply with a given reactive to total ratio, as shown in Fig. 1. The STATCOM can be used to this goal, and, simultaneously, to restore, as far as possible, the voltage level inside the wind farm.

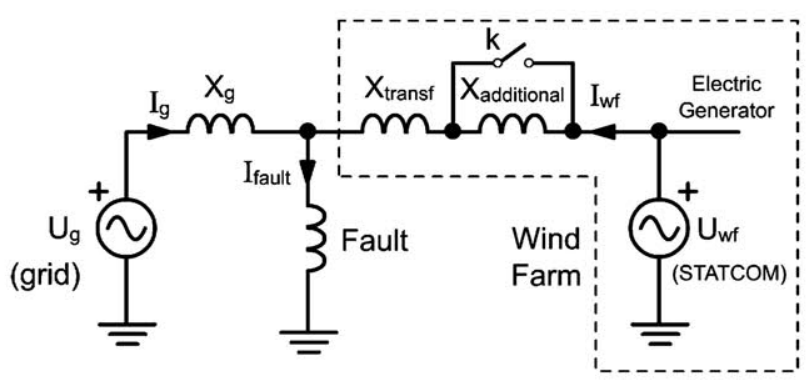

Fig. 4. Additional impedance to withstand nearby grid faults.

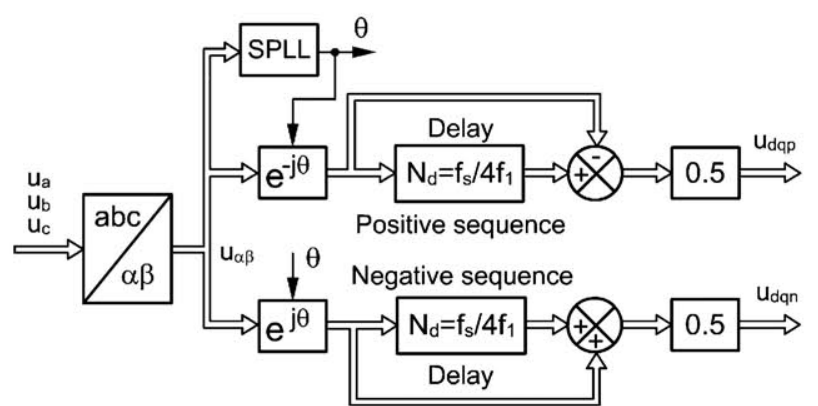

Fig. 5. DSC: Positive and negative sequence detector for both the grid voltage and the wind farm voltage. $N_{d}$ are the samples in delay, $f_{s}$ is the sampling frequency, and $\mathrm{f}_{1}$ is the grid frequency. See Table 1 for other subscripts.

The possible grid faults can be balanced or unbalanced. In the case of unbalanced faults [17], the control system needs to calculate the values of the positive and negative sequences of the grid voltage and grid current $[18,19]$. In this work, the algorithm used for this purpose was the Delayed Signal Cancellation (DSC) [20,21], whose block diagram is depicted in Fig. 5 . This system calculates the values of the positive and negative sequences of the grid voltage expressed in the $\mathrm{d}-\mathrm{q}$ frame. There is no zero sequence because the grid neutral is not connected.

Next, each of the outputs of the DSC was connected to a Vector Controller (VC), Fig. 6. Four DSC were programmed, one for each sequence $(p-n)$, and one for each axis $(d-q)$.

The VCs corresponding to the $\mathrm{d}$ axis for both sequences regulate the reactive power injected by the inverter in the grid, while the VCs corresponding to the $\mathrm{q}$ axis control the active power delivered. To restore, as far as possible, the grid voltage value after the dip, the reference value used for the positive sequence regulator is the nominal grid voltage. However, in the case of the negative sequence, the reference value for its regulator is zero because the objective is to eliminate the unbalance.

Also, it is necessary to measure the active and reactive powers at the point of coupling, $P_{w f}$ and $Q_{w f}$, in order to check the grid code compliance for LVRT. These powers, delivered by the wind farm to the grid, can be calculated in $\mathrm{d}-\mathrm{q}$ axis as:

$P_{w f}=u_{w f d p} \cdot i_{w f d p}+u_{w f q p} \cdot i_{w f q p}+u_{w f d n} \cdot i_{w f d n}+u_{w f q n} \cdot i_{w f q n}$

$Q_{w f}=u_{w f d p} \cdot i_{w f q p}+u_{w f q p} \cdot i_{w f d p}+u_{w f d n} \cdot i_{w f q n}+u_{w f q n} \cdot i_{w f d n}$

The synchronization was done by calculating the argument of the spatial vector corresponding to the positive sequence of the grid voltage, measured in the generator terminals:

$u_{\alpha}=\frac{3}{2} \cdot u_{a} ; u_{\beta}=\frac{\sqrt{3}}{3}\left(u_{b}-u_{c}\right) ; \theta=\operatorname{atan} \frac{u_{\beta}}{u_{\alpha}}$

For this reason, the value of the $u_{w f d p}$ component is always the module of the spatial vector and the value of $u_{w f} q p$ is always zero. In other words, the direction of the $d$ axis coincides with the spatial

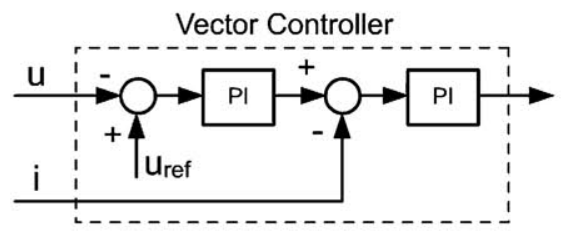

Fig. 6. Vector Controller programmed for each positive and negative sequence and for each $d-q$ axis. 


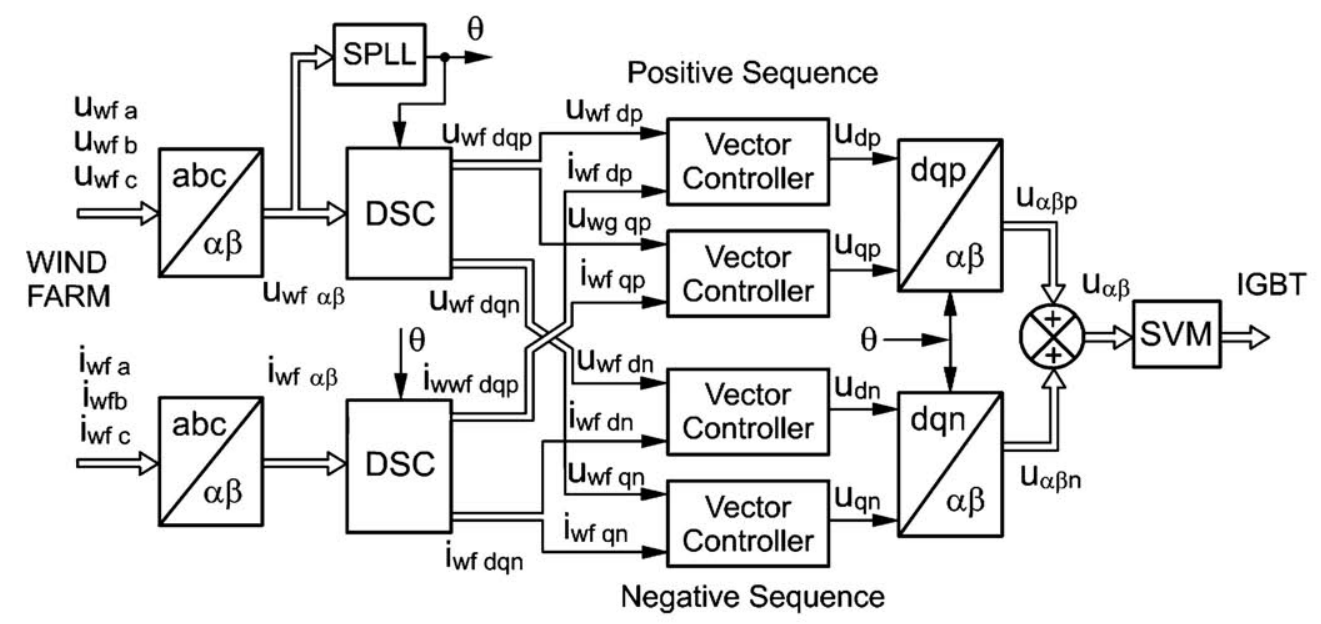

Fig. 7. Full control algorithm: two independent DSCs for the voltage and the current, and four Vector Controllers.

vector of the grid voltage at the generator terminals. Also, in the case of a balanced system in steady state or during a three-phase fault, the electric powers delivered by the wind farm are:

$$
P_{w f}=u_{w f d p} \cdot i_{w f d p} ; Q_{w f}=u_{w f d p} \cdot i_{w f} q p
$$

On the other hand, when a three-phase fault occurs, the d component of the grid voltage, $u_{w f} d p$, reduces its value while the values of the rest of sequence components remain null. In this situation, the VC corresponding to the $\mathrm{d}$ axis of the positive sequence reacts by increasing the $d$ axis voltage generated by the inverter, $u_{d p}$, in order to increase the reactive power injected to the grid.

The results of the VCs of each sequence, once they have been referred to a fixed reference frame, are combined to generate the firing signals for the IGBT using a Space Vector Modulator (SVM) algorithm, Fig. 7.

\section{Experimental results}

This section describes the test rig developed in this work to test the STATCOM behavior, schematically depicted in Fig. 8, and compiles the experimental results obtained for several types of faults. These laboratory tests reproduce the more representative cases of voltage sags at the connection point of a wind farm due to grid faults in the electrical network it is connected to. The study has been focused on checking the compliance of the wind farm with the grid code, and on investigating the feasibility of the proposed solutions.

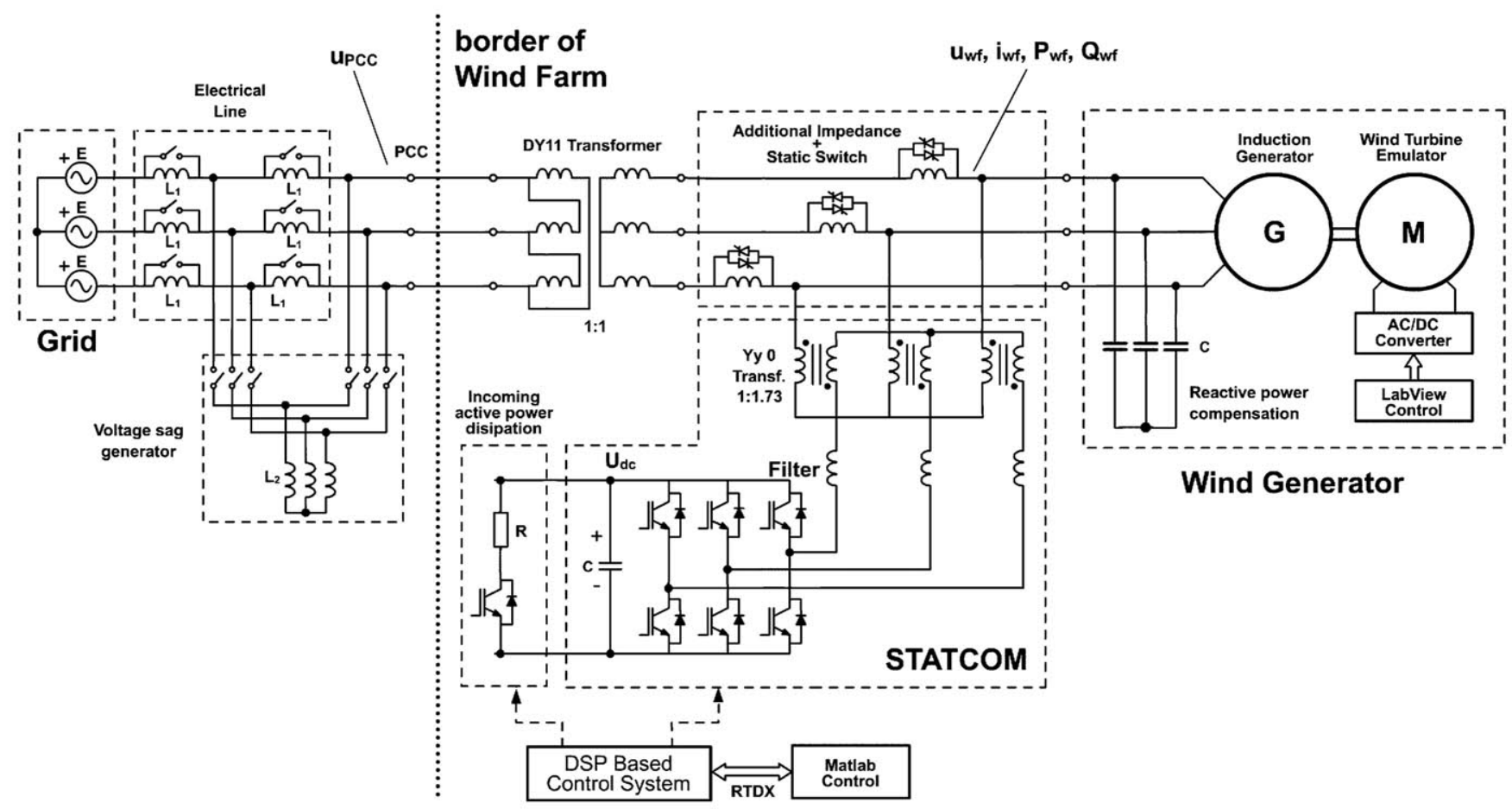

Fig. 8. Layout of the test rig used in the laboratory experiments. 


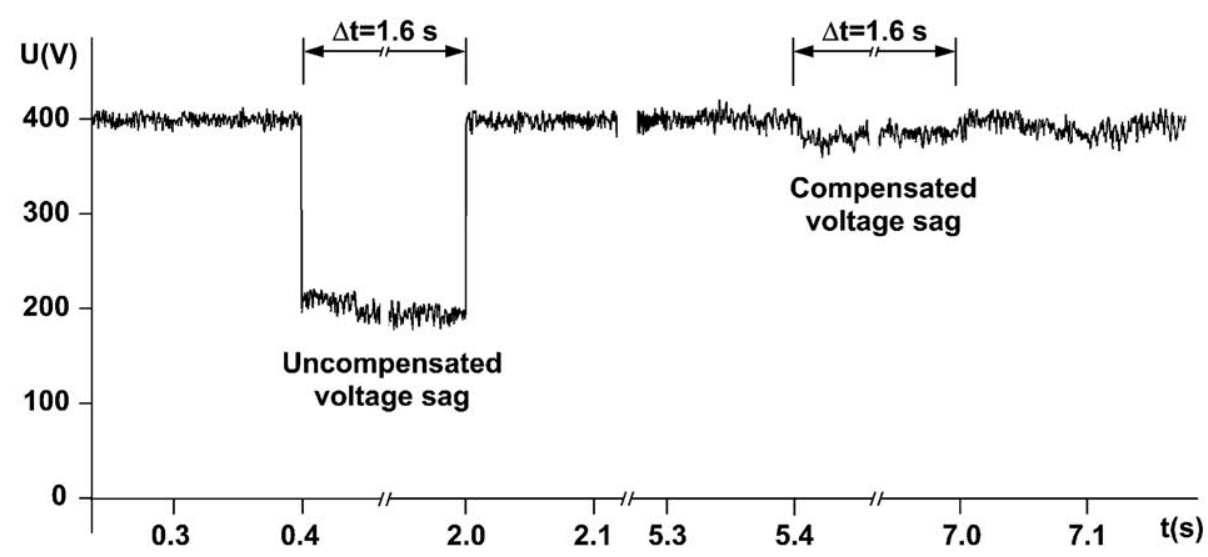

Fig. 9. Voltage in the point of coupling, in the compensated (left) and the uncompensated (right) three-phase fault.

To carry out the laboratory tests, a scaled system with all the most important subsystems of a wind farm was built, as shown in Fig. 8. It was composed by an induction generator driven by a wind turbine emulator, a coupling transformer, an electrical line with linear inductances, a voltage sag generator (for distant and nearby faults emulation), STATCOM, and a system of short-circuitable impedances.

The turbine emulator consists of a DC motor and an AC/DC electronic converter controlled with LabView, similar to [22]. It is composed by a $3 \mathrm{~kW}$ DC motor driven by a commercial microprocessor-based DC converter easily configurable. The converter is controlled by means of a PC and an input-output data acquisition device. The influence of the emulator on the tests was insignificant due to the short duration of the voltage dips compared with wind changes.

The control algorithm of the STATCOM was programmed on the Texas Instruments TMS320F28335 Digital Signal Processor (DSP), and the sampling and switching frequency was set to $3 \mathrm{kHz}$, similar to that of actual inverters in wind generation. The data captures and the control interface in the laboratory tests were carried out using the Real Time Data Exchange (RTDX) feature implemented in the DSP with Matlab-Simulink, as described in [23].

\subsection{Three-phase fault distant from the wind farm}

This subsection presents the experimental results obtained with the test rig when a three-phase short-circuit occurs in a point of the power system far from the connection point of the wind farm. As it was mentioned before, in this case, the impedance between the fault and the wind farm can be high and, therefore, the restoration of the grid voltage is not complicated. In fact, in the performed experimental test, the reactive power injected by the STATCOM was able to practically restore the grid voltage at the connection point. Fig. 9 shows the value of the grid voltage during two subsequent three phase faults: the first, without using the STATCOM, for the sake of comparison with the second, in which the fault is mitigated by the reactive power injected by the STATCOM.

To comply with the grid code, the wind farm not only has to restore the grid voltage to avoid a disconnection, it also has to deliver reactive power during the fault. Fig. 10 shows the active and reactive power measured in the point of coupling for the compensated case.

Note that, if the line impedance is relatively high, with a limited amount of reactive power, the STATCOM achieves the grid voltage restoration at the point of coupling. However, the amount of reactive power that the STATCOM can inject into the grid is limited, so it may be difficult to comply with grid code requirements when the line impedance is lower (i.e., when the electrical distance to the fault is lower).

Moreover, if the voltage at the wind generators is almost restored, so that their LVRT capability is guaranteed, the wind farm injects into the grid the same active power as it did before the fault. But, if the voltage at the connection point cannot be fully restored, the ratio $I_{\text {reactive }} / I_{\text {total }}$ is low and the grid code is violated. To increase

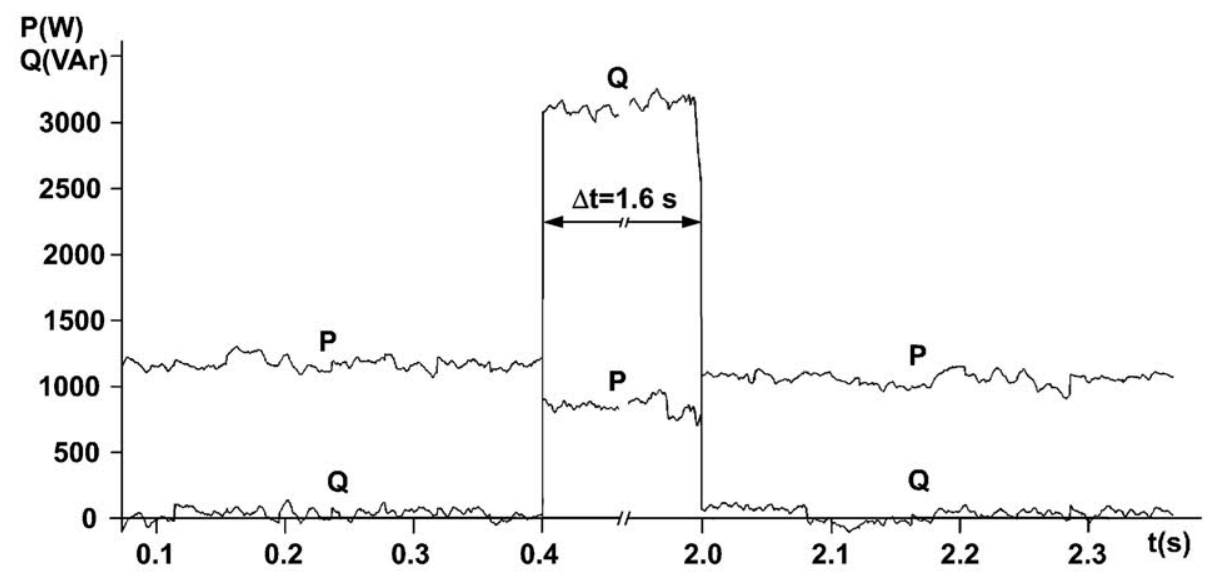

Fig. 10. Active and Reactive power measured in the point of coupling. 


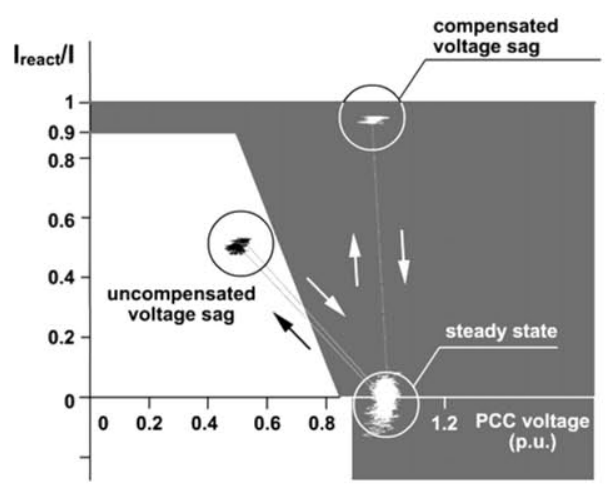

Fig. 11. $I_{\text {reactive }} / I_{\text {total }}$ ratio vs. voltage at the point of coupling, before and during a compensated and an uncompensated three-phase fault.

the ratio, the proposed solution is the use of a braking resistor in the DC bus of the STATCOM, so that it absorbs a part of the active power generated, in order to increase the $I_{\text {reactive }} / I_{\text {total }}$ ratio [24].

By combining the recorded time evolutions of voltage (as in Fig. 9) and active and reactive powers (as in Fig. 10), the time can be eliminated (as in Fig. 1 ) and the evolution of the $I_{\text {reactive }} / I_{\text {total }}$ ratio can be represented as a function of voltage. Fig. 11 shows the so obtained operating points, where three different clouds of operating points can be clearly noted, corresponding to the steady state previous to the fault, and the regions to which the system moves during the voltage sag, depending on whether the sag is compensated or not with the STATCOM. The shaded area represents the allowed operating points, according to the Spanish grid code [4]. If no compensation is carried out, the operation point moves to the banned area. But, if the STATCOM tries to compensate the sag, the operation point moves to the allowed area. In this case, the increasing of the $I_{\text {reactive }} / I_{\text {total }}$ ratio was achieved by combining: the reactive power injection in the grid, carried out by the electronic converter; and the absorption of a part of the generated active power by the braking resistor.

An additional interesting result of the tests can be seen in Fig. 12, where the recorded generator speed is shown in the cases in which the sag is compensated and uncompensated. If the voltage sag compensation is carried out, the wind turbine speed remains constant, since all the incoming mechanical power is absorbed, in part by the grid and in part by the braking resistor. If there is no voltage compensation, the grid cannot absorb all the incoming mechanical power during the sag and the generator speed increases. Note that the speed variation in the asynchronous

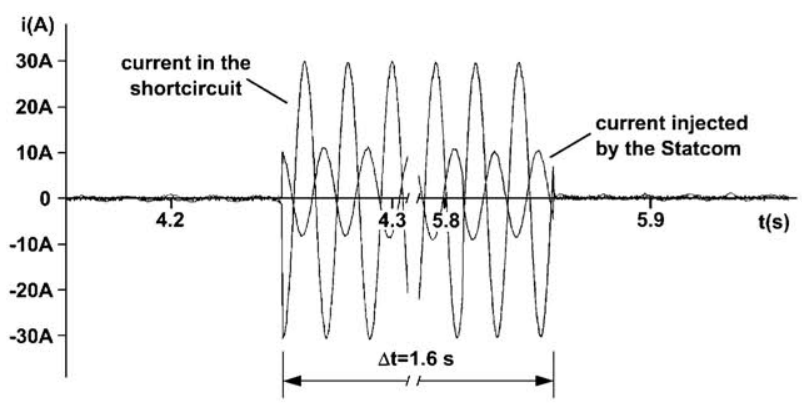

Fig. 13. Current in the short-circuit and current injected by the STATCOM.

generator does not imply a frequency variation in the grid (in fact, during the experiment, the frequency was kept constant at $50 \mathrm{~Hz}$ ).

\subsection{Three-phase fault near the wind farm}

This Subsection presents the most relevant aspects of the wind farm behavior when it faces a deep voltage sag due to a three-phase short-circuit in a point of the external network close to the plant. This case represents, for example, a short-circuit in terminals of the wind farm or in its vicinity. As mentioned before, in this case, the series impedance between the fault and the wind farm is low, or even zero in the worst case. This makes impossible the restoration of the grid voltage.

In Subsection 4.1, the STATCOM was able to supply the contribution of the wind farm to the fault current, so that the level of the internal current coming from the generators is similar to the prefault level, and the voltage sag is practically compensated at the point of coupling. However, in the case described in this Subsection 4.2 , due to the low line impedance (in combination with a low fault impedance), the fault current level is some times higher than the converter maximum current. Fig. 13 shows the waveforms of the fault and the STATCOM currents recorded in a test with a shortcircuit in the terminals of the laboratory wind farm.

The experimental test reproduces the worst situation, since there is no impedance between the fault point and connection point of the plant. The transformer short-circuit impedance is the only impedance between the fault point and the STATCOM. As a consequence, the voltage at the point of coupling cannot be restored, as it can be seen in the recorded waveforms of Fig. 14.

As stated before, when the voltage dip is detected, the control system reacts. It tries to compensate the sag and, also, to comply

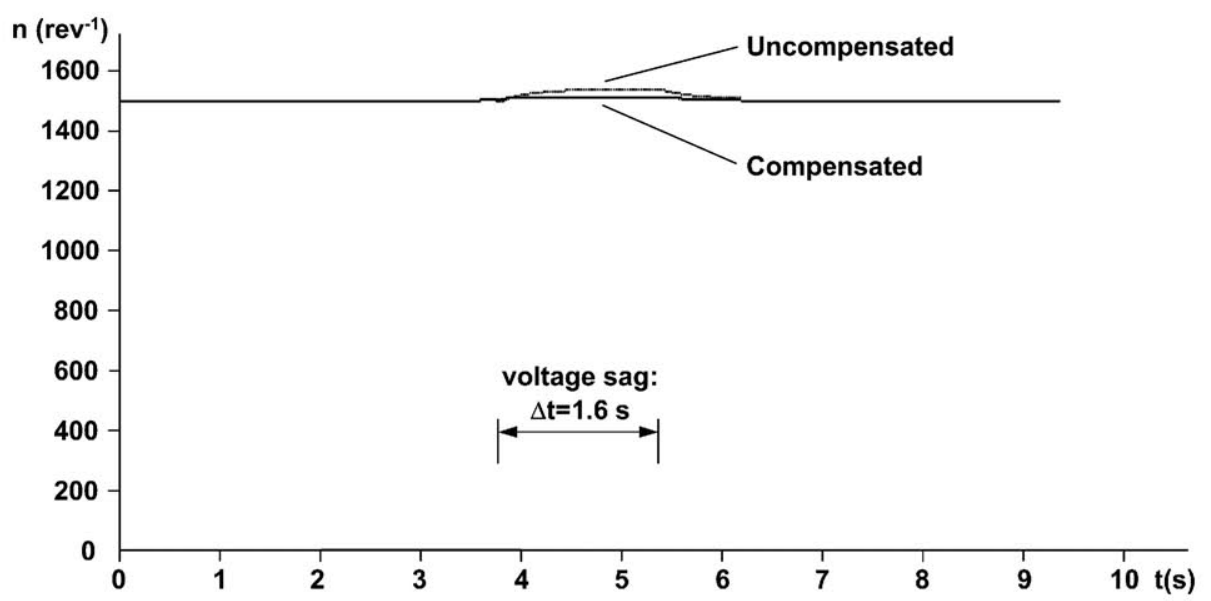

Fig. 12. Generator speed during a compensated and an uncompensated voltage sag. 


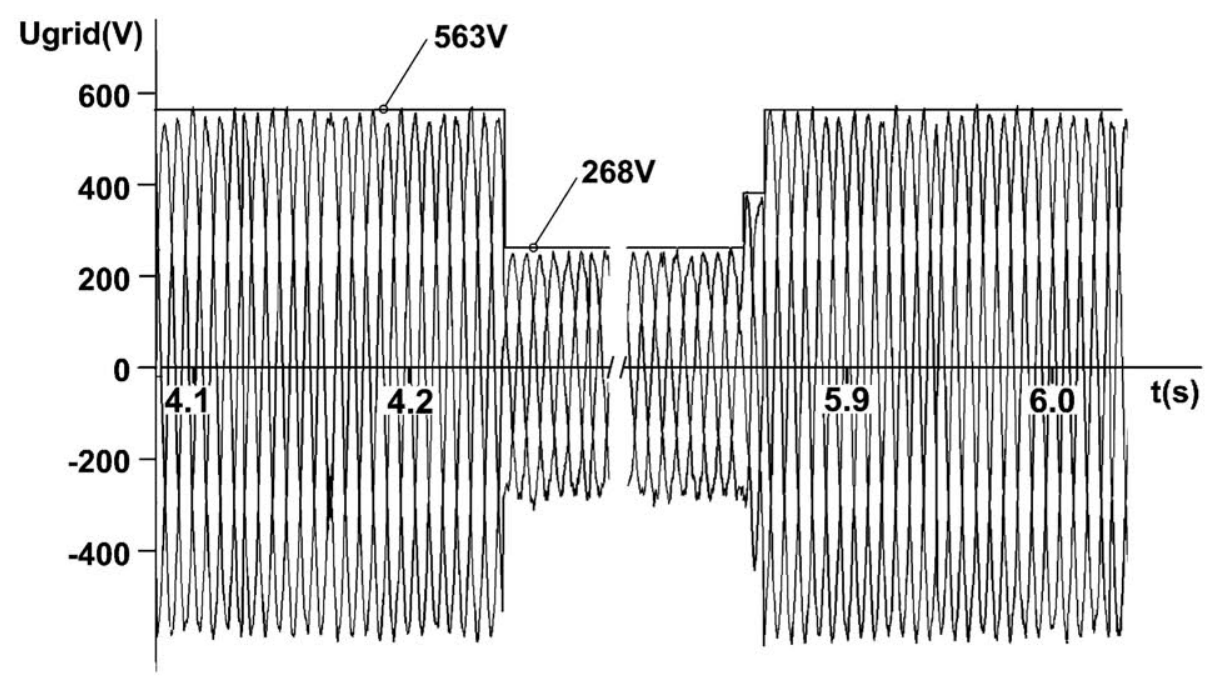

Fig. 14. Voltage waveforms at the point of coupling during a three-phase fault.

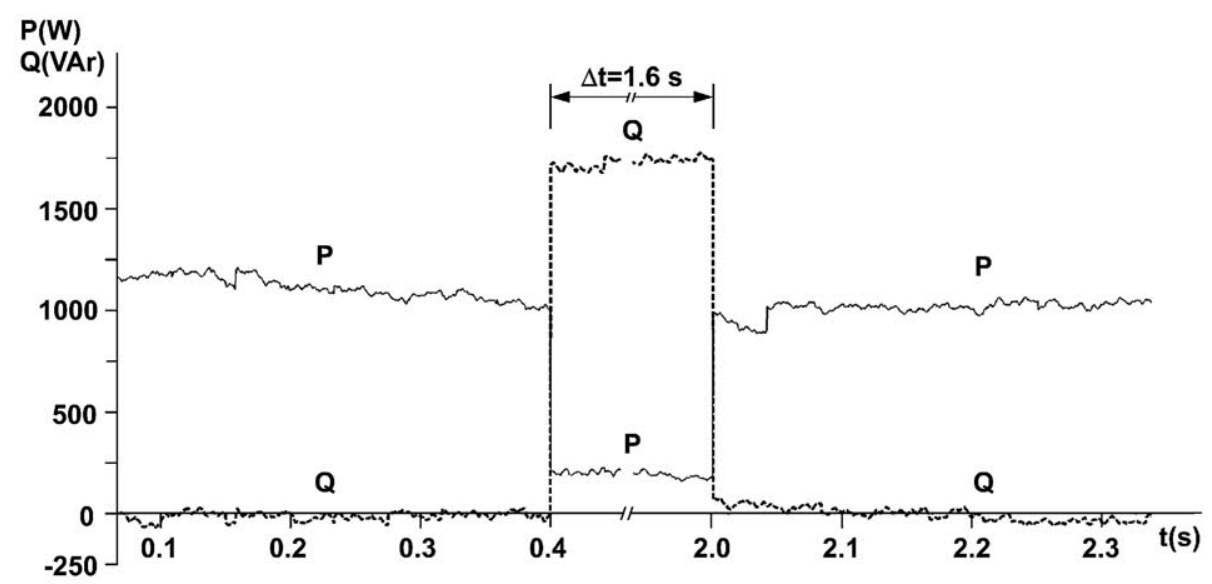

Fig. 15. Active and reactive powers measured in the point of coupling during the voltage sag.

with the code reactive requirements. The STATCOM delivers reactive power and absorbs active power by means of the braking resistors. Fig. 15 shows the recorded active and reactive power supplied by the wind farm to the electric network before, during and after the voltage sag. Before the fault, the wind farm was operating with unity power factor. And, during the fault, it quickly changes to almost exclusively deliver reactive power to the grid.

Fig. 16 shows how the cloud of operation points during the three-phase fault remains within the allowed area, although the grid voltage has not been fully restored. Fig. 16 also includes the evolution of the operating point in the case of an uncompensated voltage sag, for the sake of comparison.

The results displayed in Fig. 16 may lead to the erroneous conclusion that the operation of the wind plant is adequate. On the contrary, as the voltage could not be restored in the connection point, or in the wind farm, the generators can trip. I.e., they can lose their LVRT capability, due to the undervoltage or the overcurrent. As stated in Section 2, a feasible solution to improve the restoration of the voltage within the wind farm limits is the connection of additional impedances in series with the grid connection (see Figs. 4 and 8). Fig. 17 shows the partially restored grid voltage at the point of coupling, $u_{P C C}$, and the voltage within the wind farm, $u_{w f}$, depending on whether additional impedances are used (b) or not (a).

When additional impedances are not used during the fault compensation (a), the voltage at the PCC and the wind farm are almost equal. In contrast, when additional impedances are connected during the fault (b), the static switches are opened, although the grid voltage hardly changes, the remaining voltage inside the wind farm increases. With an adequate selection of the impedance value, this increase can be high enough to avoid the

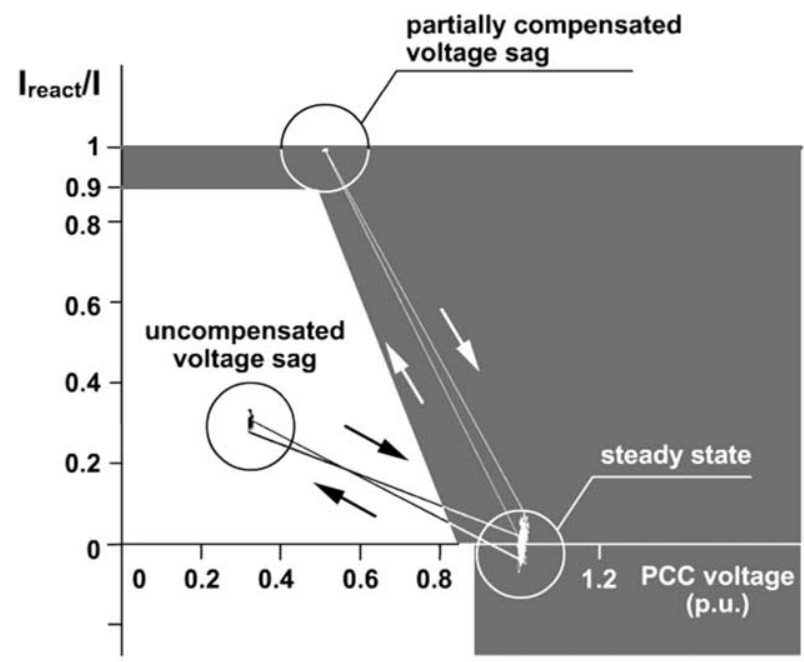

Fig. 16. $I_{\text {reactive }} / I_{\text {total }}$ ratio vs. voltage in the point of coupling during an uncompensated and a compensated three-phase fault. 


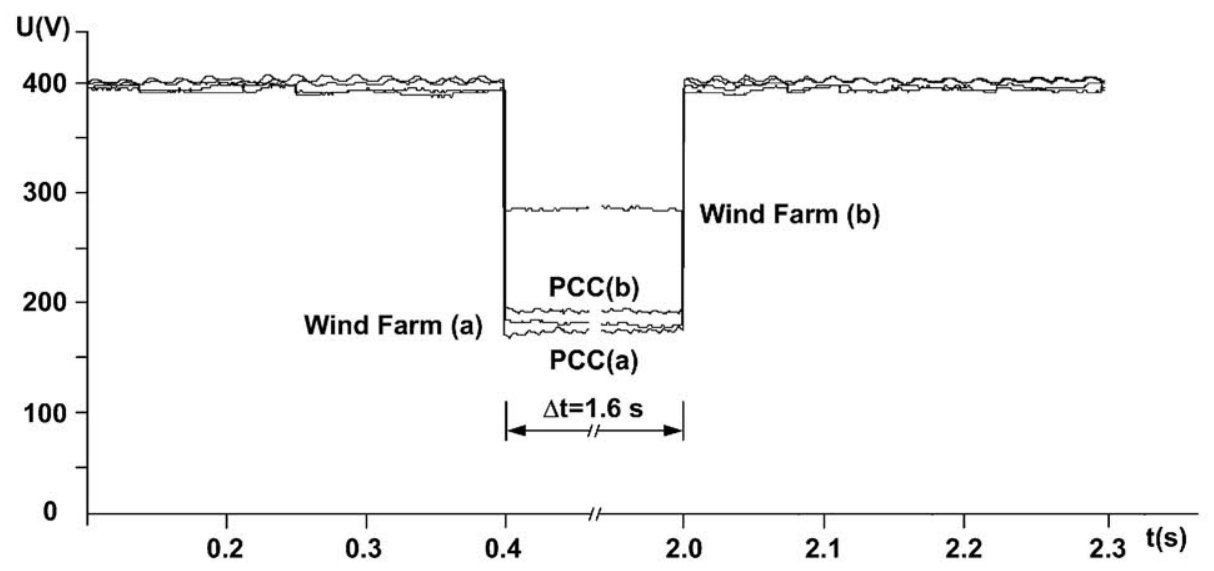

Fig. 17. Voltage level at the point of coupling, $u_{P C C}$, and whithin the wind farm, $u_{w f}$. without the use of additional impedances (a), and with them (b).

disconnection of generators. Determining the most appropriate value of the impedance, and its inductive or resistive character, requires an analysis with numerous factors, including: the electrical topology of the wind farm; the characteristics of the disturbance that has to be withstood, defined by the grid code; the electromechanical properties of the generators; economic considerations; the voltage-time and current-time characteristics of protections; and the coordination with the stabilization strategies [16].

It is important to note that, although the grid voltage is not fully restored, the wind farm fully complies with the grid code: on the one hand, its generators do not trip and, on the other hand, the reactive requirements are met, as it can be seen in Fig. 18. Moreover, from the

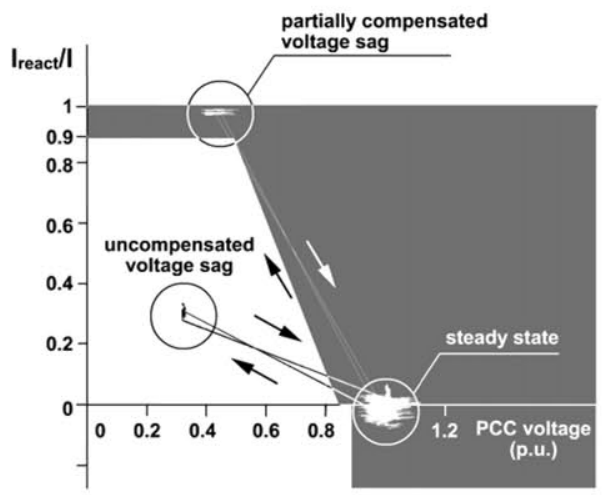

Fig. 18. $I_{\text {reactive }} / I_{\text {total }}$ ratio vs. voltage in the PCC when additional impedances are connected in series with the wind farm. point of view of the power system, the important thing is the effect of the code compliance, not the compliance itself. In Fig. 18, this effect can be clearly appreciated by comparing the cloud of operating points when the voltage sag is compensated and when it is not.

\subsection{Phase to phase grounded fault distant from the wind farm}

In the case of unbalanced faults (phase to phase or singlephase), the grid code requirements are slightly different. For example, the Spanish grid code [4] does not allow the absorption of active or reactive power by the wind farm during the fault time or in the period following the subsequent clearing.

Several tests were carried out with the laboratory test rig to investigate the behavior of the wind plant when facing a phase to phase short-circuit. Fig. 19 shows the resulting wind farm voltage, $u_{w f}$, expressed in terms of the positive and negative sequences in the $\mathrm{d}-\mathrm{q}$ frame. In the first voltage sag shown in the figure, no compensation was performed, representing the natural behavior of the wind plant without STATCOM. In the second voltage sag shown, the same fault was provoked, but with the STATCOM compensation enabled. Fig. 20 plots the corresponding measured active and reactive powers, showing the code compliance. Note the $100 \mathrm{~Hz}$ oscillation (two times the fundamental frequency) during the sag, due to the unbalanced situation.

\subsection{Phase to phase grounded fault near the wind farm}

A similar short-circuit is tested in this Subsection, with the only difference of a very low impedance between the fault and the wind

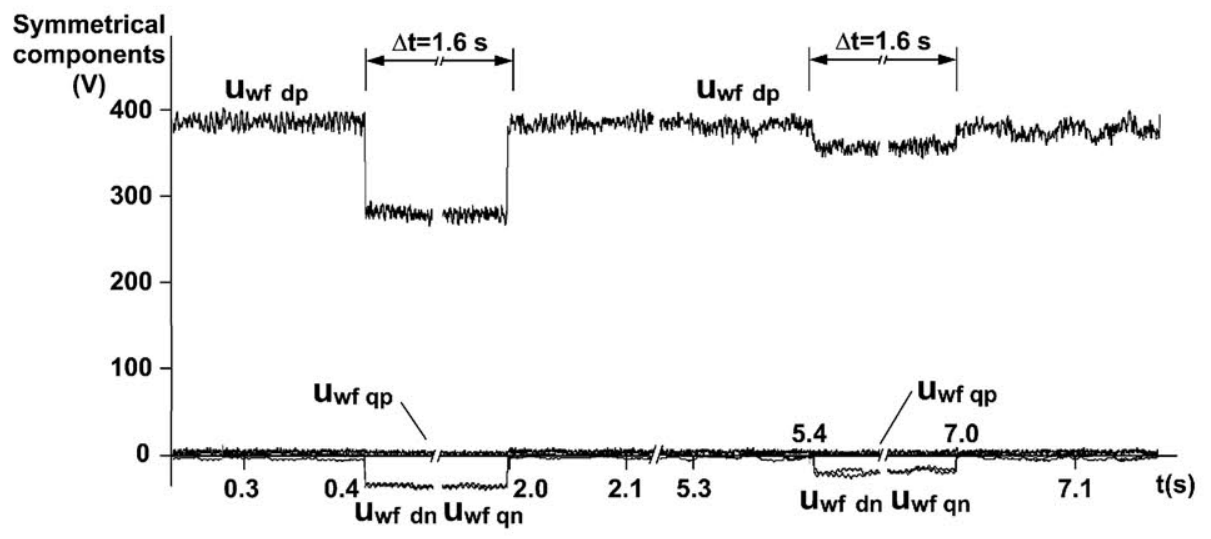

Fig. 19. Symmetrical components of $u_{w f}$ expressed in d-q frame. 


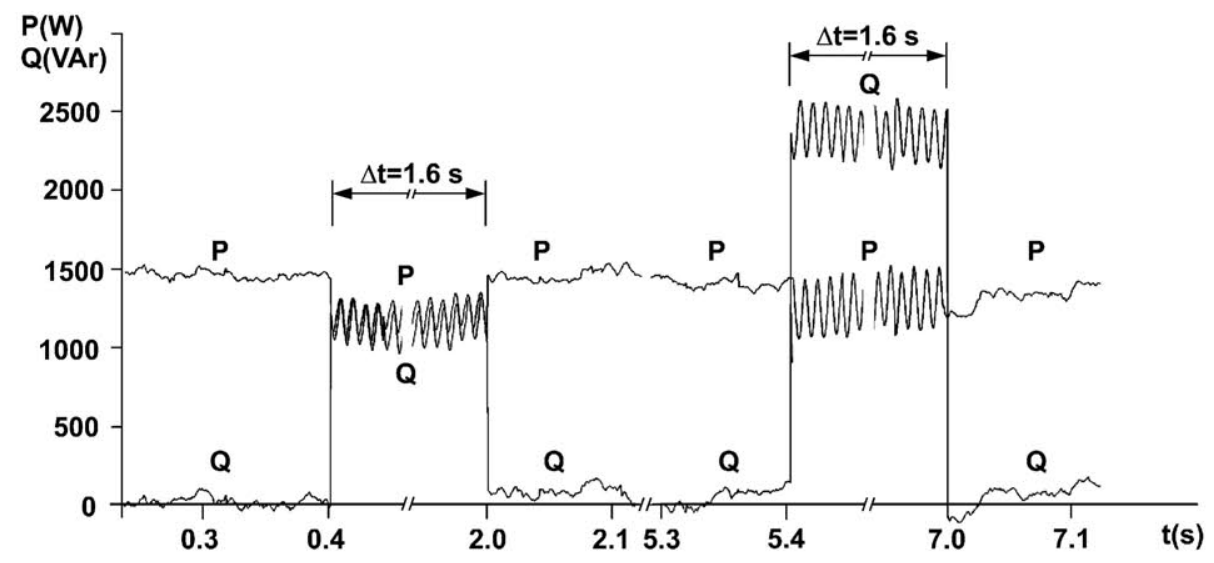

Fig. 20. Active and reactive power measured in the line during an uncompensated and a compensated phase to phase distant fault.

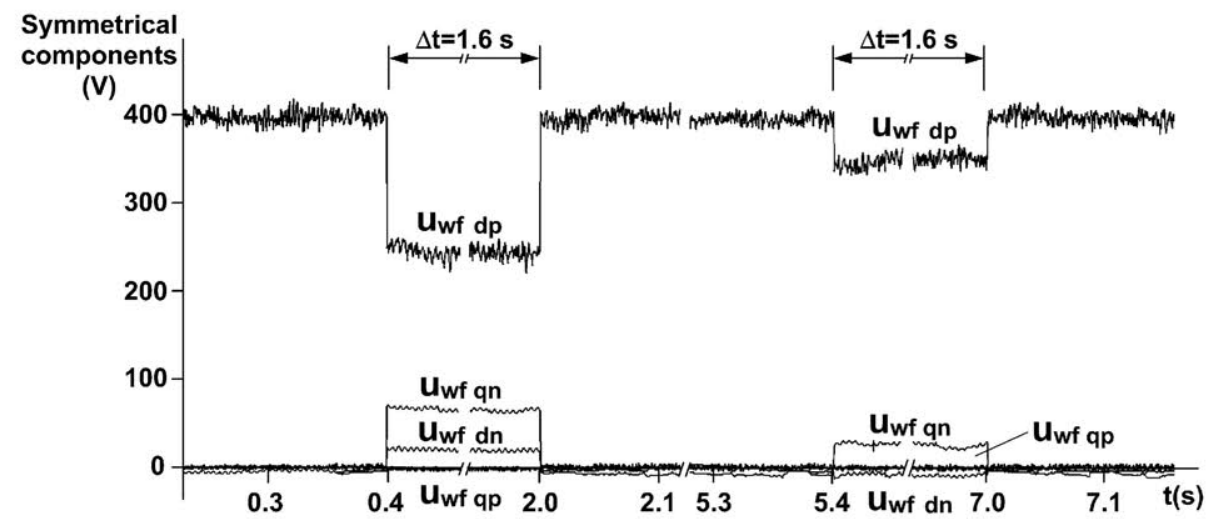

Fig. 21. Symmetrical components of $u_{w f}$ expressed in $\mathrm{d}-\mathrm{q}$ frame during the phase to phase nearby fault.

farm. Fig. 21 shows, the resulting wind farm voltage, $u_{w f}$, in the d-q frame. During the first voltage sag (left), no compensation is performed. During the second (right), the STATCOM compensation is carried out with the use of additional impedances. As it can be seen, the use of these impedances improves the wind farm voltage restoration. As in the balanced case, an adequate impedance value, or an electronic converter with higher rated current, would improve the restoration of the unbalanced voltage within the wind farm.

To show the effect of the additional impedances, Fig. 22 plots the active and reactive power flows between the wind farm and the grid, measured in the point of coupling. During the left sag, no additional impedances were connected, whereas, during the right sag, they were. In both cases, the adequate control over the STATCOM guarantees that there is no active or reactive power absorption by the wind farm.

\subsection{Single-phase fault distant from wind farm}

In case of a single-phase short-circuit in a distant point of the power system, similar results can be reported. Fig. 23 shows the symmetrical components of $u_{w f}$ during the voltage sag, without (left) and with STATCOM compensation (right). The corresponding active and reactive powers, measured in the point of coupling, are plotted in Fig. 24. In the pre-fault steady state, the wind farm operates with unity power factor. When the compensation is

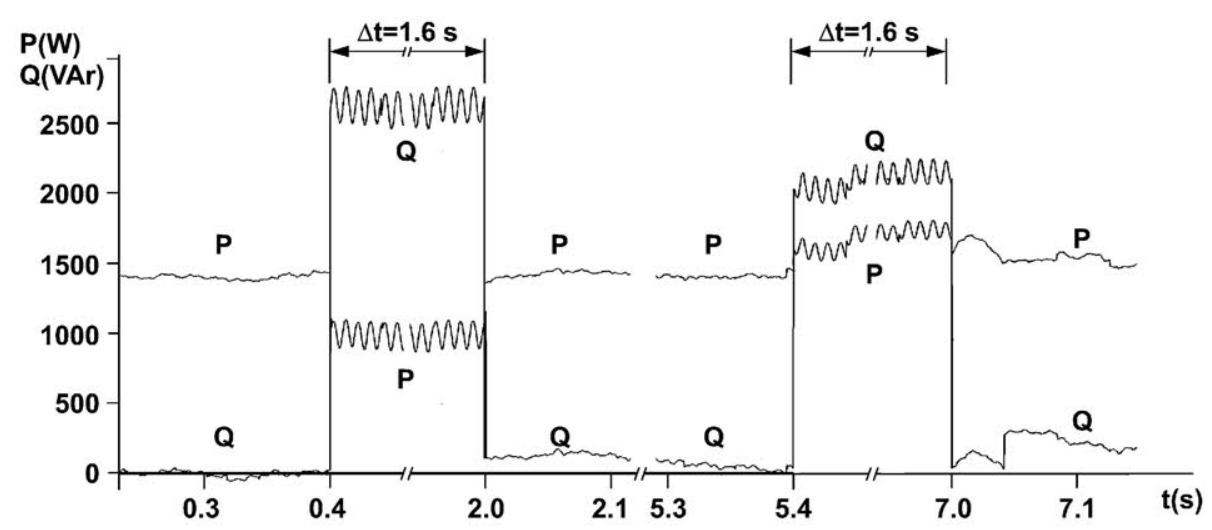

Fig. 22. Active and reactive power measured in the line, without and with the use of additional impedances during the phase to phase fault. 


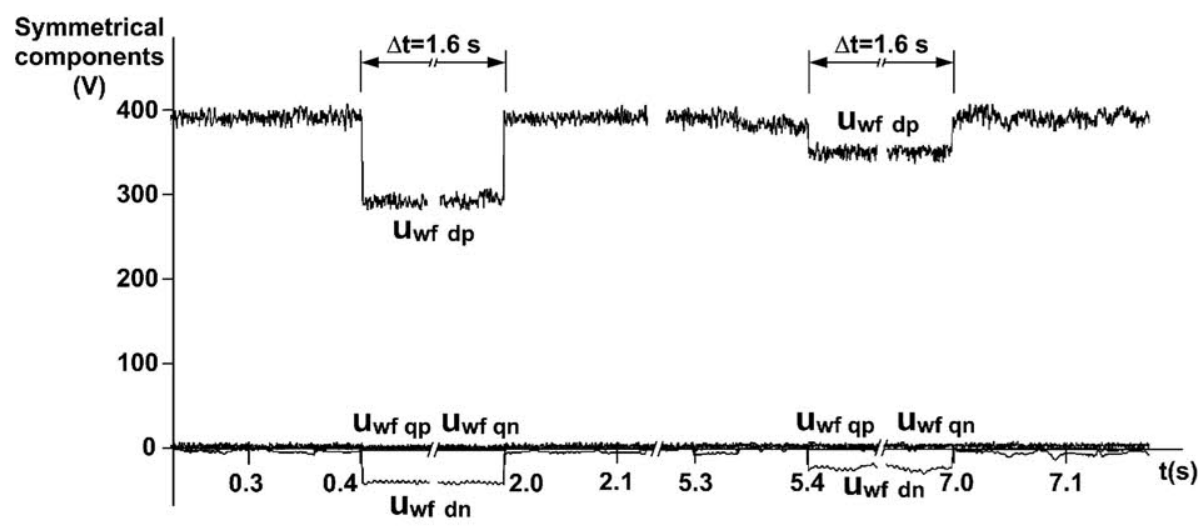

Fig. 23. Symmetrical components of $u_{w f}$ expressed in $\mathrm{d}-\mathrm{q}$ frame during the single-phase fault.

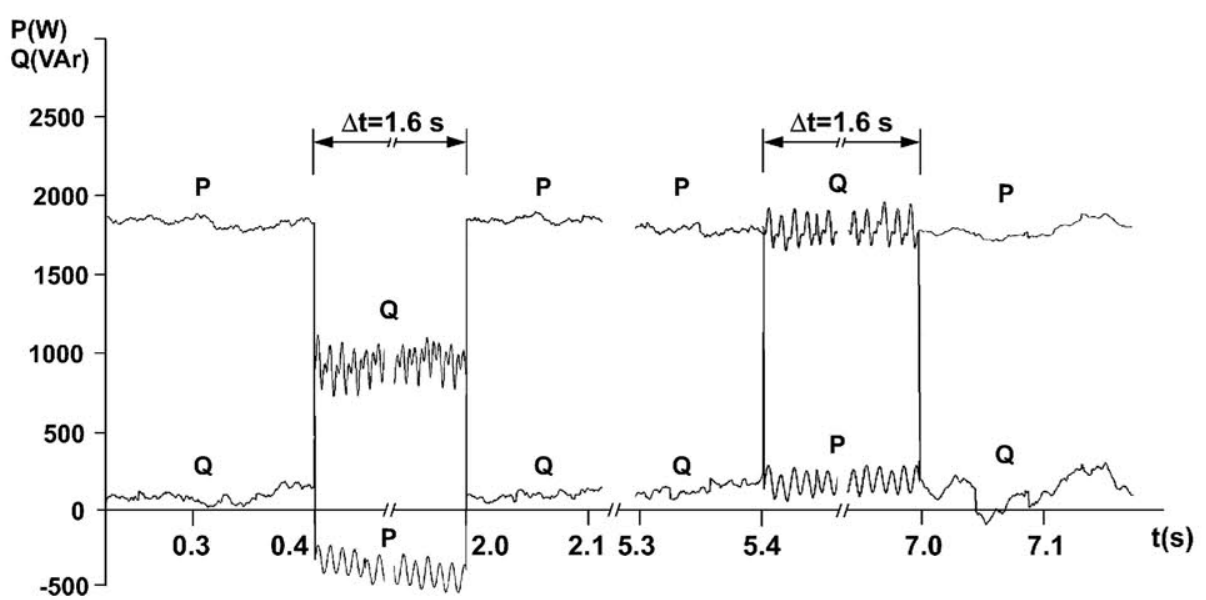

Fig. 24. Active and reactive power, measured in the line during the single-phase fault.

disabled (on the left) the grid code is not met due to the absorption of active power during the fault period. On the contrary, when the STATCOM compensation is enabled, no active power is absorbed, thus complying with the grid code.

\subsection{Single-phase fault near the wind farm}

Finally, this subsection presents the natural behavior of the wind farm when facing a voltage sag due to a single-phase short-circuit in a point of the grid close to the plant. This behavior is shown on the left part of Fig. 25 for the symmetrical components of $u_{w f}$. The natural response is compared with the behavior of the wind farm, represented on the right part of the figure, when the STATCOM compensation is enabled, along with the use of additional impedances to deal with the fault proximity. It can be seen how the negative sequence is mitigated and the positive is partially restored.

As in Figs. 24 and 26 compares the power flows during the dip when the STATCOM compensation is performed without the use of additional impedances (left) and with them (right). The compliance with the grid code is only met in the second case.

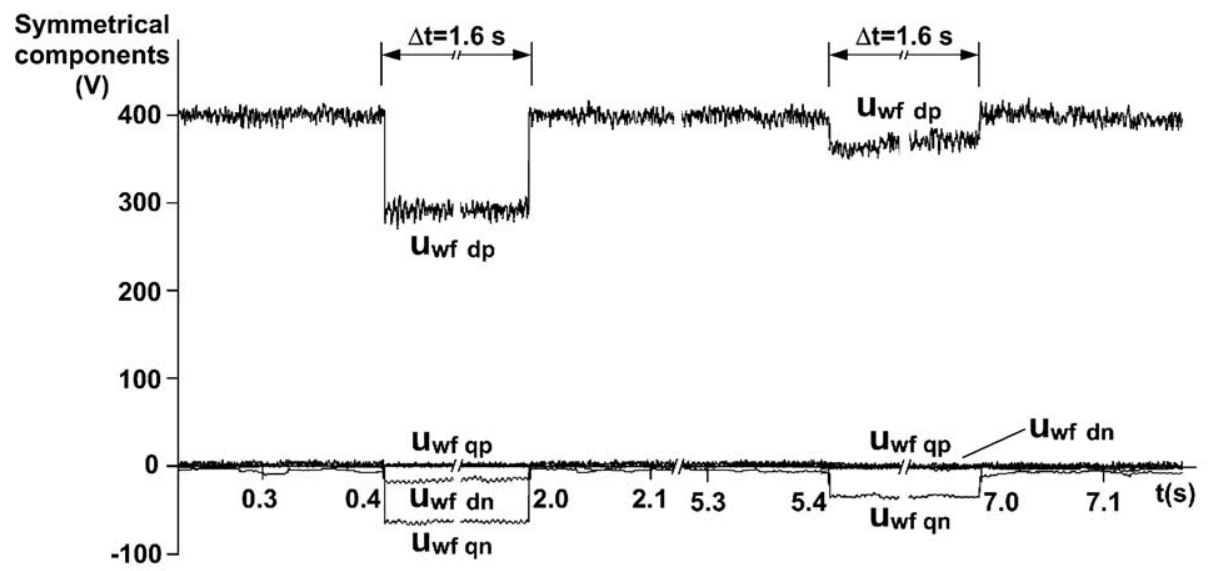

Fig. 25. Symmetrical components of $u_{w f}$ expressed in d-q frame. 


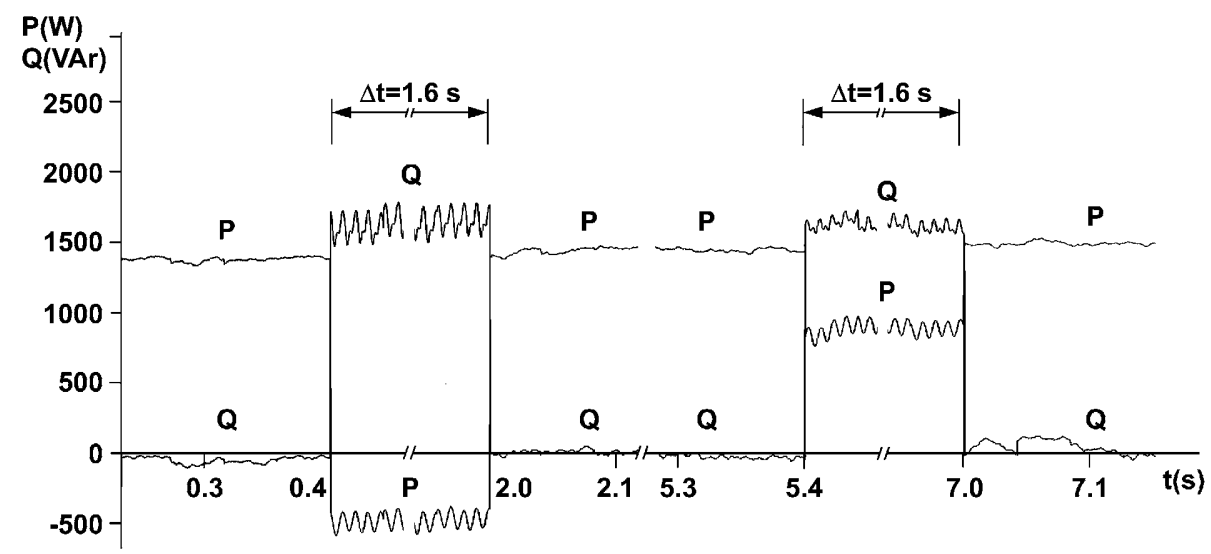

Fig. 26. Active and reactive power, measured in the line, with and without additional impedances.

\section{Conclusions}

The use of STATCOM is a valid solution for grid code compliance of wind farms with fixed speed generators. This paper has shown how the most exigent requirements can be met with some additional equipment and an adequate control strategy. In addition, the exhaustive analysis presented for every possible grid fault, balanced and unbalanced, distant or near the wind farm, can be a helpful guide when testing other possible solutions.

\section{Acknowledgements}

This work was supported in part by the Spanish Ministry of Science and Innovation under Grant ENE2009-13276, and by the Spanish Ministry of Education under Grant PR2010-0021.

\section{References}

[1] Regulation TF 3.2.5. Wind turbines connected to grids with voltages above 100 kV. Denmark: Elkraft System and Eltra; November 2004.

[2] Grid connection regulation for high and Extra high voltage, E.ON Netz GmbH, April 2006.

[3] The grid code Issue 3, Revision 16. National Grid Electricity Transmission plc, Warwick CV34 6DA, 30th May 2006

[4] Secretaria General de Energia, Procedimiento de Operacion 12.3. Requisitos de respuesta frente a huecos de tension de las instalaciones eolicas, Spain, vol. 254. BOE; 24th October 2006 [in Spanish].

[5] EL-Helw HM, Tennakoon Sarath B. Evaluation of the suitability of a fixed speed wind turbine for large scale wind farms considering the new UK grid code. Renew Energy 2008;33:1-12.

[6] Kyaw Min Min, Ramachandaramurthy VK. Fault ride through and voltage regulation for grid connected wind turbine. Renew Energy 2011;36:206-15.

[7] Molinas M, Suul JA, Undeland T. Low voltage ride through of wind farms with cage generators: STATCOM versus SVC. IEEE Trans Power Electron 2008:23:1104-17.

[8] Ramirez D, Martinez S, Platero CA, Blazquez F, de Castro RM. Low voltage ridethrough capability for wind generators based on dynamic voltage Restorers. IEEE Trans Energy Convers 2011;26:195-203.
[9] Jayashri a R, Kumudini Devi RP. Effect of tuned unified power flow controller to mitigate the rotor speed instability of fixed-speed wind turbines. Renew Energy 2009;34:591-6.

[10] AouzellagLahaçani N, Aouzellag a D, Mendil B. Static compensator for maintaining voltage stability of wind farm integration to a distribution network. Renew Energy 2010;35:2476-82.

[11] Ali $\mathrm{MH}, \mathrm{Wu}$ B. Comparison of stabilization Methods for fixed-speed wind generator systems. IEEE Trans Power Deliv 2010;25:323-31.

[12] Ramirez D, Beites LF, Blazquez F, Ballesteros JC. Distributed generation system with PEM Fuel Cell for electrical power quality improvement. Int J Hydrogen Energy 2008;33:4433-43.

[13] Bongiorno $M$, Svensson J. Voltage dip Mitigation using Shunt-connected voltage source converter. IEEE Trans Power Electron 2007;22:1867-74.

[14] Han C, Huang AQ, Baran ME, Bhattacharya S, Litzenberger $W$ Anderson L, et al. STATCOM Impact study on the integration of a large wind farm into a Weak Loop power system. IEEE Trans Energy Convers 2008:23:226-33

[15] Bollen MHJ. Understanding power quality problems - Voltage sags and Interruptions. New York: IEEE Press: 2000.

[16] Causebrook A, Atkinson DJ, Jack AG. Fault ride-through of large wind farms using series dynamic braking resistors. IEEE Trans Power Syst 2007;22: 966-75.

[17] Bollen MHJ. Algorithms for characterizing measured three-phase unbalanced voltage dips. IEEE Trans Power Deliv 2003;18:937-44.

[18] Paap GC. Symmetrical components in the time domain and their application to power network calculations. IEEE Trans Power Syst 2000;15:522-8.

[19] Ghijselen JAL, Van de Bossche APM. Exact voltage unbalance assessment without phase measurements. IEEE Trans Power Syst 2005;20:519-20.

[20] Le TN. Kompensation schnell veränderlicher Blindströme eines Drehstromverbrauchers. ETZ Archiv 1989:11:249-53.

[21] Svensson J, Bongiorno M, Sannino A. Practical implementation of Delayed signal Cancellation Method for phase-sequence Separation. IEEE Trans Powe Deliv 2007;22:18-26.

[22] Rabelo B, Hofmann W, Gluck M. Emulation of the static and dynamic behavior of a wind turbine with a dc Machine. In: Proc. 35th IEEE power electronics specialists conference; 2004. p. 2107-12.

[23] Ramirez D, Martinez S, Rodriguez J, Carrero C, Blanco M. Educational tool for the implementation of electric drives control system with real time data exchange. Int J Eng Educ 2009;25:24-32.

[24] Wu X Arulampalam A, Zhan C, Jenkins N. Application of a Static Reactive Power Compensator (STATCOM) and a dynamic braking resistor (DBR) for the stability enhancement of a large wind farm. Wind Eng 2003;27 93-106. 